\title{
Reviewing Critical Discourse Analysis (CDA) Studies: Ideas from Chinese Scholars
}

\author{
Zhan Li Xia ${ }^{1}$ and Budianto Hamuddin ${ }^{2}$ \\ ${ }^{1,2}$ Applied Linguistic Center, Universitas Lancang Kuning, Indonesia \\ zhan.lixia97@gmail.com
}

\begin{abstract}
Received : 2019-06-08
Revised : 2019-06-12

Accepted : 2019-06-25
\end{abstract}

ARTICLE HISTORY

\section{KEYWORDS}

$C D A$

Chinese scholars

Inter-relationship

Review

\begin{abstract}
This present study discusses Critical Discourse Analysis (CDA) studies made by Chinese scholars. The rising of the studies in China seems started at the beginning of the 90s'. It is almost two decades since Chinese scholars get involved in Critical Discourse Analysis research. In a short time, the scholars showing their ability in critical discourse analysis by publishing many papers since it. This present library research aims at reviewing the CDA studies since 1990 until the present day to see the related link between discourse, control and ideology in the relationship between personal, facts, and social-cultural development in. The studies start with several definitions, origin and some leading research in Europe and America of Critical Discourse Analysis. This present study reveals that the papers produced by Chinese scholars on CDA fields since the 1990s somehow mostly discuss in the area of linguistics, political, philosophy, media studies, methodological, and theoretical studies expression. The Chinese scholars are floundered to produce Critical Discourse Analysis studies with unique research to study without limits. Recently the research shows that $\mathrm{CDA}$ has been applied to the investigation of varied discourses context to disclose social reality, focusing on the inter-relationship between discourse, power and ideology.
\end{abstract}

\section{Introduction}

Zellig Harris was the first linguist in American structural extend studies of discourse analysis in his research paper at 1952 with title Discourse Analysis, and in 1979 Roger Fowler the expert in British linguist publish his book Language and Control, a book with the regulation of critical linguistics studies. Norman Fairclough, one of professor at Lancaster University, he is a researcher in CDA practical to Sociolinguistic. He clarified the concept in his essay Language and Power.

In 1999, when Kristen Malmkjer is listed be a complement of textual analysis and conversational lessons in Linguistics of Encyclopedia, Studies of Critical Discourse Analysis formally measured as a division of DA (Discourse Analysis) and also conventional by linguistics studies.

Firstly we will talk about the definition of "discourse" before we start talking about CDA (Critical Discourse Analysis). Professor of Language at King College, Guy Cook (1989:156), he said discourse make bigger of language studies recognize to be significantly combined. According to Fairclough (1995:18), the discourse has two fundamental parts; discourse looks by public act and, and discourse as a public structure of truth. Teun V.D (1997) mentions that discourse is usually identified as a form of verbal language, what is said in public speeches, for example, or it could also refer to the design of convinced educate of thoughts, for instance, the discourse of contemporary philosophies.

Define of "discourse" by the expert are illustrate with clear that meaning of "discourse" is strong linkage both of linguistics studies and social factors and it does not only contain about words, written, spoken, or texts, but it about obsesses to strong relationship connecting language and the social ideology power. Teun Van Dijk (1998-4) says, from a critical perspective, some ideologies are "better" than others when the social project involves an attempt to achieve equity.

In (CDA) Critical Discourse Analysis, critical should to understood next to discourse as it is strongly connected with ideology. Critical Discourse Analysis interpret dialogue as an ideology because they are used to characterize the systems of attention, show in language that groups and persons exercise to see themselves, passed through of filter information, and understand the meaning of some conversation extend the ideology.

Claim by Critical Discourse Analysis, no matter if an ideology is good or bad, that depends on if that helps someone to think positive and set goals in others 
way or improve their ability they can change be better with good or bad ideology. But if he/she can't accept others bad ideology and he/she feel hopeless then stop to get a more because of others critical it depends on he/she opinion, that's mean he/she success because of their self-can't accept others negative ideology and selfish.

More to the point of "critical", for common people is not studying about a linguist, they will ask what is different between studies of critical discourse analysis and discourse analysis?

Discourse analysis is more focus on the study of texts, theory, stylistics and others like that. But critical discourse analysis is focused on the relationship between language and variety of social life, interferences, and also efforts to show up the strengthness from ideology context to speaking and its mean social interaction and also social structure is two factors are emphasized by critical analysis. As a result, the people who have the strength to speak the issue maybe has a relative concept to speak until final about that issue and can affect others beginning of the issue (Hamuddin, 2015).

According to Wodak, 2001, the definition of critical, "critical" means not taking things for granted, opening up complexity, challenging reductionism, dogmatism, being self-reflective in my research, and through these processes, making opaque structures of power relations and ideologies manifest. "Critical", thus does not imply the common sense meaning of negative, rather sceptical. Proposing alternatives is also part of being "critical". (Wodak's definition of "critical" in Resigl \& Wodak, 2001, Chapter 2) [17].

Ruth Wodak is professor expert in applied of Linguistics since 1991 years. She was awarded the Wittgenstein Prize to elite explore in 1996, which made a few years of the continuous interdisciplinary group explore possible. Her research mainly located in Discourse Studies and Critical Discourse Analysis (CDA). Together with her colleagues and $\mathrm{PhD}$ students in Vienna, she complexes the "DiscourseHistorical Approach in CDA" which is interdisciplinary, problem-oriented and analysis changes in discursive practices over time and in a variety of types.

Beside Ruth Wodak, there is others who experts in Critical Discourse Analysis, Teun A.van Dijk, defined "a type of discourse analytical research that primarily studies the way social power abuse, dominance and inequality are enacted, reproduced, and resisted by text and talk in the social-political context" (van Dijk: 1999).

CDA has made many processes since the 1970s in the international community. However, CDA studies in China did not begin until Chen (1995) [8] introduced critical linguistics in 1995. Since then, academic research has attracted considerable attention in the linguistic circle, and plentiful accomplishments have been achieved. CDA studies in China began in 1995 when Chen introduce critical linguistics. And actually, CDA has made process since 1970 in the world community. Although China is late to know and studies more about CDA, that does not make them to late chasing achievements, they recognized in the world with the achievements of their research in CDA. In China, Lan and Wang, reviewed CDA studies from June until December, they are analysis all research article related eleven linguistics articles, and they make their invention and findings.

In total, there are 53 investigates articles that are a delegate and trustworthy give out the samples of their studies. The journey of their discovery consists of:

a) Begin in half of the 2005 year there are only 2 have a certain quality, interesting worlds to CDA are increased in 2006, and until 2009 there are 31 articles have a certain quality, and with that's showed domestic academic is began to interesting to studies of CDA.

b) Academic linguistics journals are sited a mounting pressure on CDA studies. There are seen by in June 2008 Foreign Language Research established a studies column for CDA, which propose CDA a positive place for development.

c) The figure of researches focus on Critical Discourse Analysis study are increasing. Fiftythree articles are the intervention of 49 writers.

d) Articles on theoretical introduction and review studies took up the overwhelming majority because Critical Discourse Analysis studies are mostly concentrate on introduction and prestige of research in international academic society. Only some article of CDA analyses of exact text and discourse.5. Prof. Xin, the linguist who the most stand out in comparative Critical Analysis between English discourse studies and Chinese discourse studies and this news report terms in number one newspaper in New York, The New York Times and China Daily, but unfortunately there is no scholars in China try to use the same way.

e) The number of articles on practical research is more than articles on academic research, and this tendency continues from 2009, but if look by methodologies investigations, there are more article on theoretical research than on practical research.

Chinese scholars still have weakness even if they have complete big performance in studies of CDA, the first reason is point and lining of CDA studies in others country especially American have been comprehensive to ideology, research on racial, political discourse analysis, studies of migrant, research on media and language, bureaucratic 
discourse, social life discourse, studies of institutional and others. On China, they are instead to focus and stressing of evaluation foreign studies research. Some existing research at home engage legal discourse, advertising discourse and discourse of institutional, but there is also not deep enough to investigate the internal instrument of CDA.

The material of studies CDA at home is too incomplete and late for Chinese scholar, because when other worlds have walk half way to studies CDA, they just need to start to know what is CDA, there is the second reason weakness to learn CDA for Chinese scholar, even though there is argument on responsive topics of political and small issues, the resources for discussion are new and different for Chinese materials.

Lan and Wang's Chinese scholar evaluate research have presented that stress on studies of CDA in China has been uneven from the research of theoretical to claim of CDA studies to the examination of extract discourse in varied contexts of social.

Li (2004), Presented his views of CDA in sensible studies and teaching of language in more than a few aspects by analyzing the setting, methodology and also the process of CDA studies.

Furthermore, the dedication of CDA falsehood in discourse is a factor of social that have contribution usefully to a revolution of social-life. Because of this, Fairclough opines that studies of critical analysis can support social progress and there is a reason domestic scholars need to active the tool of CDA studies of social life discourse to explore the connection between discourse and society.

Yuan (2001), showed to the public that CDA of political discourse is meant to find out more about the social function of studies of discourse and factors of socio-cultural.

Jiang (2003), digging up very distant sources about the principles and power of connection language by analyzing news of English and sharping out the international media inundated with English news subjective and the world under enemy control audience's ideology.

Team of analysis studies about CDA has summarized the latest trend about studies of CDA in China, and that is showed to foreign language teachers to know how to drawing material about political and social leaning of news rumour about Chinese topic in others foreign media group.

Seen from inclusive progress of China economy and speed of globalization in latest years, media group of western start to go through the domestic market of Chinese. As a result, it is Chinese readers need to increase their responsive able of ideology power and relations power. In another side it's a reason teaching a foreign language is not thought to be a cut off tool to teach language to our students, but more factors of social can be measured in teaching language to show our student the important of the line in political and our social life as a social human.

\section{Method}

Development of CDA in China from 2000-2009 years are drawing by Lan and Wang (2010) from the overall picture. For this part and another part that tracks details of theoretical and methodological studies and practical studies on CDA in China to show to the public.

CDA theories theoretical and methodological is pure foreign (abroad), and like what are authors draw in the first part, studies about CDA in the home especially for research CDA in language put in research on CDA. One scholar in China, Xin (1996), comprehensive observation on the core of CDA theoretical in foreign country studies at the 1980s until 1990s, and the results of finding are a tag on:

a) Firstly, the important of social language context, and the functional of Halliday and also propose an easy way to faced CDA studies.

b) Secondly, the finding of Language and Control Fowler (1979), is current about the base of practices, he showed effect between ideology and discourse in social and also connection about the strengthening of control and the finding is stressing on parts of language answering "how and why".

c) Finally, Fairclough, one scholar from abroad are stressing on process power of ideology can control and influence language aspects, and there are directed by burly society. To reach three of the plans applied studies above, Xin at 1997 do study research about English discourse by looking from various aspects among others, concentrate, transformation, classification on the character of ideology-that is survived in adding up. In making a study of general CDA for the English language. In the report of this issue, Xin suggests using comparative technique CDA in the following three factors:

(1) Contrast function between semantics and a few structures of semantics also phrase in the discourse of English issues.

(2) I have investigated successive English news report about one issue from the same organization to check out viewpoint by another reporter.

(3) Investigated news report about the same issues or trends issues from other organizations to explorer different viewpoint. 
Xin (2002), are reviews methodologies of CDA studies the common methodology bring AFG to be a main line and source of structure from intensity projected by Thompson evaluated the research of ideas from three factors of proper social-historical and re-interpretation.

At 2004, Xin gives a clue to show his perspective with a few questions relating to studies of CDA on the denigration on CDA.

CDA in the function of discourse analysis studies is still in development because of prematurity; advocates have understood the curb of CDA on discourse analysis studies.

Some of the analysis of CDA studies emerges to be hard, which specify that columnists have imagined too far from studies of CDA. Up there, so many scholars in studies of CDA have established the following few points:

a) The strong point by CDA of linguistics and pragmatics studies is their can more clearly and intensely in understanding discover the effect of talkative and society has crafted by discourse study.

b) Without deepening studies linguistics and pragmatics, analysis insincerity rationally to make clear intuitional of discourse conception.

c) The analysis formation of language required to sustain and confirmed by other answers of discourse side.

d) Analysis needs recognition by deducing and exemplify discourse, and the step of illustration needs to be obvious for other scholars to inspect the investigate effect using the same way.

e) Analysis needs to be understood by themselves because the conclusion of study can be changed if there are have modification or amendment by information and background run.

At 2001, one of the scholars in China, Ji evaluated a few techniques of CDA studies. Three of the technique is following by systemic-function analysis that the one technique is known by us, and it's the original technique and the secondly there is intertextual analysis, their technique is worth the productivity and ingenuity of studies of discourse analysis pure begin from the fad of inter-textuality the last, historical analysis.

At 2004 Dai and Chen, two of scholars in China, take out a related analysis and converse the control of ideas by creation reports by online. From the genesis, theories, substances and accomplishments by CDA Li and Zhang at 2007 try to illustrate the main place.

Not different from others features of public or social life studies, research of CDA also faced some complicated situation when investigate or research focus are modifying and so many worth and also insights from others intuitions and social group along with the transform make a new confronts by how to investigate the obtaining the critically of changes.

At 2009, Chinese scholar, Zhang development an artificial theoretical structure to analyzed discourse on the interest of general functional linguistics studies. Artificial of that mostly stress at the multimodal structure of discourse at a few stages, the following stages are:

a) The first level is the perspective of ethnicity.

b) The second level is the perspective of the live condition.

c) Third, the level of semantic study.

d) Fourth, formal level.

e) Last, substance of media level.

Zhang also set onward the link among structures of grammatical, the framework of discourse, figure elements of grammar (consists of member, shape, and period), pointed out that variety of non-lingual media, present plentiful discourse statement options.

China scholars in theoretical and methodological of CDA studies mostly track the same way with European scholars, but they are using few original theoretical and methodological from China where have been intending. Chinese scholar is conformed to strange theories from European scholars to pertinent China investigate.

\section{Result and Discussion}

The Studies of CDA has a strong foundation to apply the basic of CDA practical studies and Critical analysis have got benefit by different viewpoints of CDA to investigate a variety of discourses among if there is, announcement, legal discourse, political discourse, medical discourse, fictional discourse, discourse of education, TV media discourse, speeches and others. In about five years later, in linguistics and media area studies, Chinese scholar has completed so many efforts in investigating the critical subjects in a variety of types of discourse, planning to expose the link between influence, ideology and discourse and there is newest research findings are as follows:

a) In $2009 \mathrm{Xu}$ and $\mathrm{Du}$ did take the function of ideational, interpersonal, and textual as an analytical instrument of SFG to evaluate two or few information reports from reporters or TV stations to look at features of categorization, modality and transitivity. They are doing that to look and utter if ideology influences to manage the discourse and how social covering by ideology from apparently of purposing of the statement. News official is appropriate to support their benefits country and the provide party political. In 
the end, if we read news from online or newspapers, we need to understand seriously news statements to knowing the supporting point of reporters.

b) 2009 Yang put forward that ideology of discourse aspires to get and keep the control to make up the public. He also maintained the discourse of legal in China or abroad is an application of harmony ideology through explored a link among influence, discourse and ideology and the conclusion, discourse of legal studies is area and contest of control.

c) At 2009 again, Yan and Zhao try to analyzed structure of modalities by speech about conflict of war and harmony peace in worlds where talking by John McCain and Barack Obama to show function of manipulative and persuasive from modalities of legal discourse studies and this analyzed is inspired by Halliday's SFG classification of modalities Fowler and theory by Van Dijk about analyzed of ideology in modalities. Findings in research demonstrate were using of modalities in legal discourse is best ideas or tactic and also to show the important of delivery point view and beliefs of speeches and also inflict their view to the listener where has goals with totally.

d) Next, to 2010, Xie and Li are famous scholars in China try to learn about speeches by the president of the US, George Bus, the speeches are a purpose to influence the readers in different ways. The speeches try to control the audiences with their ideology inclination.

e) Zhang and Liu (2011) [26] pointed out that the theoretical framework of critical linguistics needs improving to stress the features of the language. By analyzing and understand the lexicalgrammatical features of certain discourse, they summarized the basic principles of social factors and ideological elements in the discourse and concluded that ideational meaning leaves some of the information aside by employing particular grammatical patterns and interpersonal meaning realizes ideological features by employing particular lexical patterns to express implicit and explicit standpoints.

f) Based on research by Zhang and Liu at 2011, they show up that the structure of theoretical of linguistics critical must develop to more focusing on elements on language. They are doing that by understanding and explore lexical grammar and discourse studies. Zhang and Liu also review the fundamental standard of public aspect and ideology.

g) Wang, Sun, and Geng, at 2011 stressing in ideologies trends from reports by NYT about China. They are starting from explorer news reports about China in NYT from perspective supposed and try to understanding trending ideologies inside. They also show up that using interpersonal can change focusing and make a negative influence to make up China image in international public. Geng finds NYT placed meaning of ideologies with lining in reporting the news about China with legalizes and its make Bad Chinese image for a long time in International public.

h) Inspired by the 3-D model by Fairclough and lexical-grammar language by Halliday, at 2012 Wu exposed the link among discourse, control and ideology by harmony test discourse and social perform of TV. He is drawing is an advertisement of cosmetics or beauty tools, shown by the TV with publishing ideas about using, their life styles and also values in live with trying to persuade people who watch their ads to buy and use their product. Because of that person who watches a TV need to understand what values delivered by ads TV and getting information in ads and should to be critical be careful to understanding ads.

i) Based on Wen in 2012, is discourse can work out the strength of college students knowledge, social category, and organization. Therefore, college students of discourse take a different tactic look at by states and their advantages in the link of control. And the latest trend from Students College is standard of sending messages by mobile phone.

j) At 2012, Chen and Ji try to applied studies of CDA in the development of critical of students. Firstly, Ji argues about the important of critical reading skills, and then he recommended efforts to the student get better in reading skills. And next, Chen makes a type of effective and possible to teach students from choosing from newspapers or English language magazines CDA following by levels of semantics, discourse and also syntax to awaken students about important of critical reading.

Furthermore, findings applied about studies of CDA in latest years can be confidential by two types. First types are a focus on English language discourse, contained political speeches, media advertisement, talking conference, news reports, short language and others, with aims of showed the relation between controls and ideology in discourse.

Second types, attempt to placed findings in first types, actually is to fixed teaching of reading the English language in China with wishes students in China can read and think critical by themselves. In all of the findings, there is still have a weakness in this aspect. I have started with that, about a few studies research reports about issues about reputed of media in western. And then there are no inclusive of CDA 
studies discovering discourse issue in three of linguistics outlines. And finally, Studies of CDA especially concentrate in language disappearing hiding ideology in discourse.

\section{Conclusion}

As a part of text-linguistics studies and also the best way to take discourse analysis studies, CDA has goals to the related link between discourse, control and ideology and it's attesting is discourse helping joining of public in political efforts, support constitutional in social of realism, relation between personal, facts, and social-cultural development. According to types of CDA by Fairclough and SFG Halliday, scholars in China in this ground is applied CDA in understanding various shapes and make out many accomplishments.

\section{Acknowledgement}

This research was supported/partially supported by Applied Linguistic Center, Dept. of English Education, FKIP Universitas Lancang Kuning. We thank our colleagues who provided insight and expertise that greatly assisted the research, although they may not agree with all of the interpretations/conclusions of this paper.

\section{References}

Bin, X. (2000). Critical Linguistics and the Critical Analysis of English News [J]. Foreign Language Education, 4.

Bin, X. I. N. (2002). On the Methodology of Critical Discourse Analysis [J]. Journal of Foreign Languages, 6.

Dai, W., \& Chen, Y. (2004). Theories and Methods of Critical Discourse Analysis. Foreign Languages Research, 4.

Delu, Z., \& Xiuli, L. (2011). Lexicogrammar in Critical Discourse Analysis. Journal of Ocean University of China (Social Sciences), 2.

Du Juan, X. L. (2009). The Analysis of News from the Perspective of Critical Discourse Analysis [J]. Foreign Language Education, 4.

Fairclough, N. (1992). Critical Language Awareness [M]. London: Longman,

Fairclough, N. (2001). Language and Power [M]. London: Longman,

Fairclough, N. \& Clive, H. (1995). Critical Discourse Analysis: The Critical Study of Language [M]. London: Longman,

Hamuddin, B. (2012). A comparative study of politeness strategies in economic journals (Doctoral dissertation, University of Malaya).
Hamuddin, B. (2015). DISCOURSE ON MEDIA: Bringing Hot News into ELT's Classroom Discussion. Proceedings of ISELT FBS Universitas Negeri Padang, 3, 87-95.

Tian, H. (2001). The English and Chinese political discourse: Contrastive and Critical Analysis. Journal of Tianjin University of Commerce, 21(6).

Van Dijk, T. A. (1998). Ideology: A multidisciplinary approach. Sage.

Van Dijk, T. A. (1999). Critical Discourse Analysis [A]. In Deborah Tannen, Deborah Schiffrin \& Heidi Hamilton (Eds.).The Handbook of Discourse Analysis [C]. Oxford: WileyBlackwell,

Xie, H., \& Li, L. (2010). Critical Discourse Analysis of News Reports. Journal of Shayang Teachers College, 3.

Xin, B. (1996). Language, power and ideology: Critical linguistics. Modern Foreign Languages, 1, 21-26.

Yan, Shiqing; Zhao, Xia. (2009) Modality in Political Discourse and Its Critical Discourse Analysis. Journal of Suzhou University (Philosophy \& Social Science). 2

Yang, D. (2009). Critical Discourse Analysis of Power Awareness in Legal Discourse. Journal of Ningxia University (Humanities and Social Sciences Edition). (9). 